\title{
Evaluation of LL 37 Lipoprotein As Innate Immunity Marker among Sudanese Patients Cutaneous Leishmania
}

Corresponding Author: AbdElkarim A. Abdrabo; email:

abdrabokarim@gmail.com

Received 21 February 2019 Accepted 12 May 2019

Published 30 September 2019

Production and Hosting by

Knowledge E

(c) Ayat H. Bakr et al. This article is distributed under the terms of the

Commons Attribution

License, which permits

unrestricted use and

redistribution provided that the original author and

source are credited.

Editor-in-Chief:

Prof. Mohammad A. M. Ibnouf

\section{G OPEN ACCESS}

\author{
Ayat H. Bakr ${ }^{1}$, Abugroun E. A. ${ }^{2}$, AbdElkarim A. Abdrabo ${ }^{3}$, Omeyma A. \\ Mohamed $^{4}$, Mokhtar M. A. ${ }^{5}$, and GadAllah Modawe ${ }^{6}$ \\ ${ }^{1}$ Department of Microbiology, University of Science and Technology, Khartoum, Sudan \\ ${ }^{2}$ University of Science and Technology, Khartoum, Sudan \\ ${ }^{3}$ Department of Clinical Chemistry, Faculty of Medical Laboratories Science, Al-Neelain \\ University, Khartoum, Sudan \\ ${ }^{4}$ Department of Clinical Chemistry, Faculty of Medical Laboratories Science, Sudan International \\ University, Khartoum, Sudan \\ ${ }^{5}$ The Institute of Endemic Diseases, University of Khartoum, Sudan \\ ${ }^{6}$ Omdurman Islamic university, Faculty of Medicine, Department of Biochemistry, Omdurman, \\ Sudan
}

\section{Abstract}

Background: The leishmaniasis is a group of diseases with a broad range of clinical manifestations caused by several species of parasites belonging to the genus Leishmania. LL-37/hCAP18, the only cathelicidin in human, is expressed as an 18$\mathrm{kDa}$ preproprotein. The most prominent function of cathelicidin is their ability to inhibit propagation of a diverse range of microorganisms, which occurs at a micromolar range. Objective: The study was aimed to evaluate the LL37 plasma level in Leishmania Sudanese patients.

Methods: In a case-control study, 300 subjects were enrolled (200 as case and 100 controls); $5 \mathrm{ml}$ venous blood was collected in EDTA container, then plasma was obtained and stored frozen at $-80^{\circ} \mathrm{C}$. LL 37 was estimated using competitive ELISA The data were analyzed using SPSS version 21.

Results: The results revealed that 115 (57\%) of Leishimania patients were male and 85 (43\%) were female. Plasma LL 37 level was significantly increased in Leishmania patients $(1.30 \pm 0.71)$ compared to the control $(0.21 \pm 0.20)$ with $(p$-value 0.000$)$.

Conclusion: Leishmania patients had higher levels of plasma LL37, suggesting effective antimicrobial immunity process enhancing healing of cutaneous leishmaniasis.

Keywords: cathelicidin, LL37, innate immunity, Leishmania, Sudan

\section{Introduction}

The leishmaniases are a group of diseases with a broad range of clinical manifestations caused by several species of parasites belonging to the genus Leishmania (Family: Trypanosomatidae). The Leishmania parasite, a haemo-flagellate protozoan organism, 
is exclusively transmitted by the bite of a female sandfly of the genera Phlebotomus or Lutzomyia. There are three clinical forms of leishmaniasis: visceral leishmaniasis $(\mathrm{VL})$ including post-kala-azar dermal leishmaniasis (PKDL), cutaneous leishmaniasis (CL), and $\mathrm{CL}$ with the involvement of the mucous membranes, also called mucocutaneous leishmaniasis (MCL) [1]. CL in Sudan is similar to the disease in other endemic areas. There are three types: nodular or nodular-ulcerative, ulcerative, and diffuse infiltrative [2]. Most patients have multiple lesions of the modular or ulcerative type[3]. Typically, lesions start to heal spontaneously after approximately three months [4]. Unlike American mucocutaneous leishmaniasis, Sudanese mucosal leishmaniasis (SML) is not preceded or accompanied by cutaneous lesions. Three clinical presentations of SML have been reported: nasal, which is characterized by nasal obstruction, mucoid discharge, and slight bleeding; oral, where the patient complains of a sensation of fullness of the mouth, spontaneous loss of teeth and bleeding from the gum; and oro-nasal, where the hard palate may perforate. The disease is almost exclusively found in adult males (2070 yr) [5]. Cathelicidins are a family of evolutionarily conserved antimicrobial peptides described in mammals, birds, fish, and reptiles. This class of pleiotropic peptides is an important mediator of innate immunity against microbial pathogens and provides first-line defense against infection by promoting rapid elimination of pathogens. LL37/hCAP18 is the only cathelicidin in human [6]. The most prominent function of cathelicidins is their ability to inhibit propagation of a diverse range of microorganisms, which occurs at micromolar range [7]. Besides their direct antimicrobial action, recent studies have revealed multiple functions of cathelicidins in many other activities relating to tissue repair and innate immunity. The human and porcine cathelicidins, LL-37/hCAP18 and PR-39, respectively, for examples, have been reported to modulate the activity of immune and 7, 8, 9 inflammatory cells [8, 9]. Cathelicidins have also been shown to promote re-epithelialization of human skin wounds [10] and rat gastric ulcer [11]. The study was aimed to evaluate the LL37 plasma level in Leishmania Sudanese patients.

\section{Methods}

In this case-control study, 300 subjects were enrolled, 200 diagnosed with CL infection and 100 as control (free of $\mathrm{CL}$ infection). Blood samples were drawn after obtaining written informed consent from the patients; $5 \mathrm{ml}$ of venous blood was collected from each subject in EDTA container, then plasma was obtained and stored frozen at $-80^{\circ} \mathrm{C}$. LL 37 was estimated using competitive ELISA. Data were expressed as percentage and 
differences in variables mean levels between the two groups were tested by Student's $t$-test.

\section{Results and Discussion}

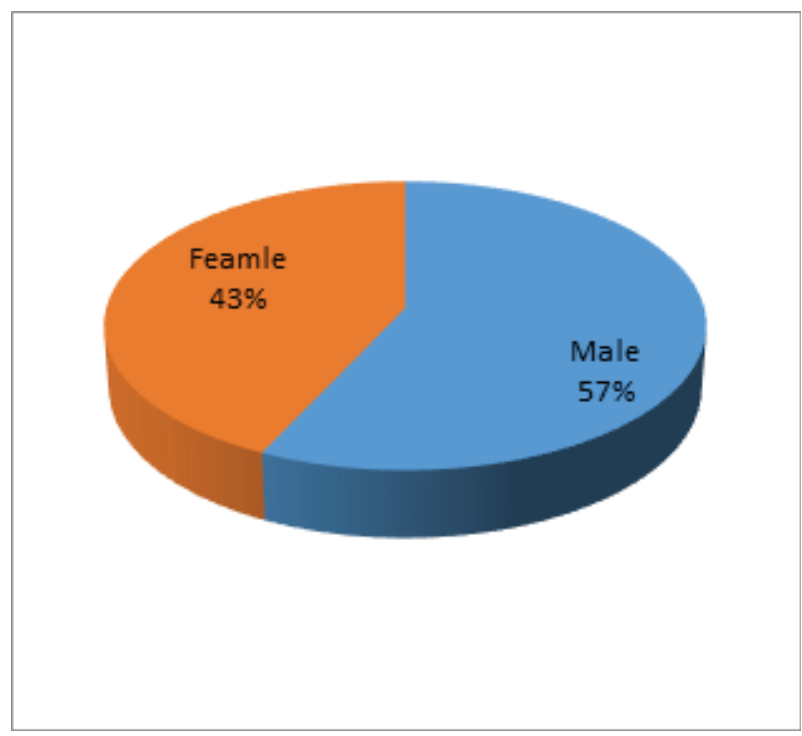

Figure 1: Distribution of patients according to the gender.

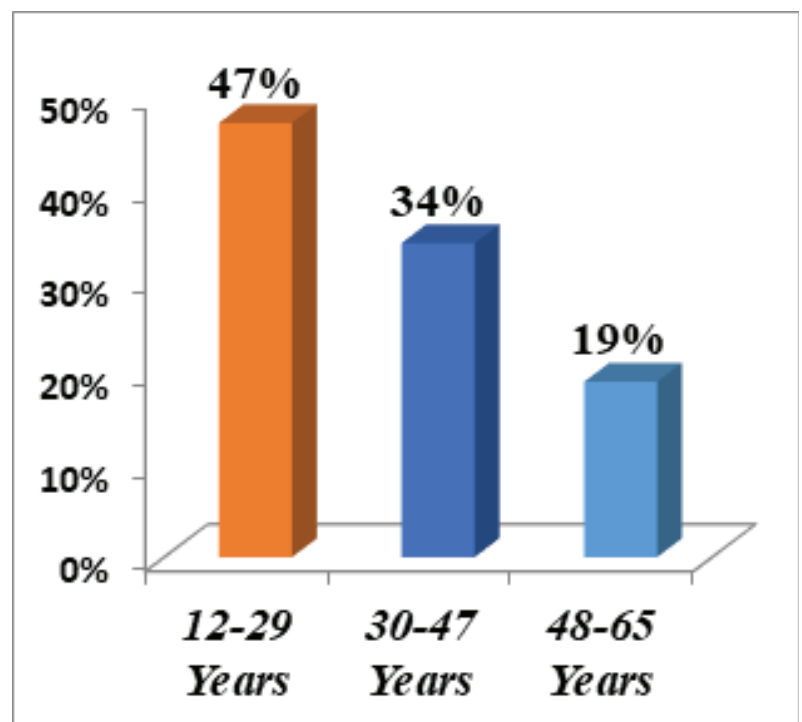

Figure 2: Distribution of patients according to age.

The results showed that 115 (57.0\%) of leishmania patients were males and 85 (43.0\%) were females (Figure 1). Regarding the age group, the higher proportion (47\%) of leishmania patients was found among the 12-29 yr old, followed by 30-47 yr, and then 48-65 yr (Figure 2). The mean values of LL-37 (plasma level $\mathrm{ng} / \mathrm{ml}$ ) for the cases was 


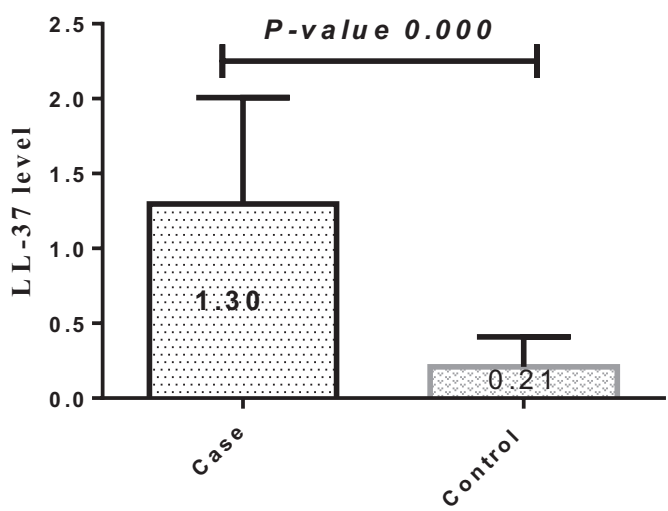

Figure 3: Mean of LL-37 across study groups.

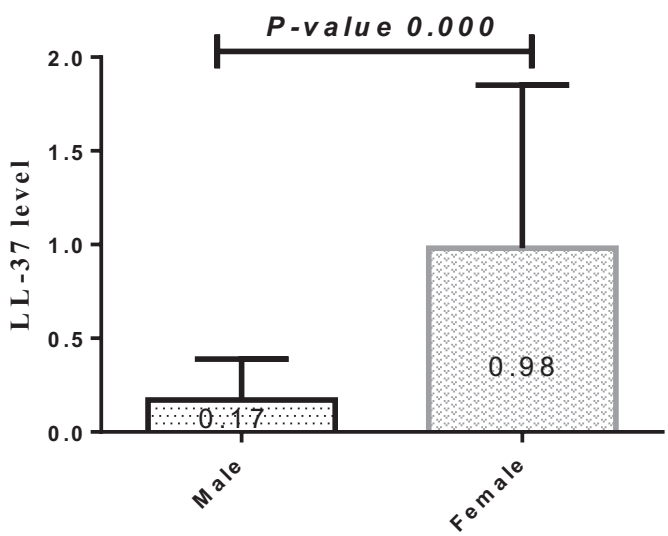

Figure 4: Mean of LL-37 across gender.

$1.30 \pm 0.71$ and for the control group was $0.21 \pm 0.25$, significant differences increase was found between cases and control groups with a $p$-value of 0.000. (Figure 3). The mean LL-37 level was significantly increased in female leishmania patients compared to male leishmania patients $p$-value 0.000 (Figure 4). LL-37 is one of the most studied antimicrobial peptides that play important roles in the innate immune system. In addition to its anti-infective activities, LL-37 stimulates local angiogenesis, acts synergistically with the epidermal growth factor receptor to promote epithelial growth, and attracts monocytes and neutrophils through formyl peptide receptors on these cells. In this way, the peptide helps orchestrate the inflammatory process [12-14]. Unlike the present study, which studied the plasma level of LL-37, Kulkarni MM et al. studied the role of this host peptide in control of the dissemination of cutaneous infection by the parasitic protozoan Leishmania, using a mouse knock-out model in cathelicidin-type antimicrobial peptides (CAMP) [15]. They found that the presence of pronounced host inflammatory infiltration in lesions and lymph nodes of infected animals was CAMP-dependent. To our knowledge, this is the first study of plasma LL37 in cutaneous leishmania patients. 
The present study data revealed an increase in plasma LL 37 levels among cutaneous leishmania patients suggesting increased expression of LL 37 is moreover able to limit dissemination of $\mathrm{CL}$. These results support the Kulkarni MM et al.'s suggestion that CAMP is crucial for the local control of cutaneous lesion development and parasite growth and metastasis [15].

\section{Conclusion}

Leishmania patients have higher levels of plasma LL37, suggesting effective antimicrobial immunity process enhancing healing of $\mathrm{CL}$.

\section{References}

[1] Osman, O. F., Kager, P. A., and Oskam, L. (2000). Leishmaniasis in Sudan: a literature review with emphasis on clinical aspects. Tropical Medicine and International Health, vol. 5, no. 8, pp. 553-562.

[2] Abdalla, R. E., Ali, M., Wasfi, A. I., et al. (1973). Cutaneous leishmaniasis in Sudan. Transactions of the Royal Society of Tropical Medicine and Hygiene, vol. 67, no. 4, pp. 549-559.

[3] El-Safi, S. H., Peters, W., El-Toam, B., et al. (1991). Studies on the leishmaniases in Sudan. 2. Clinical and parasitological studies on cutaneous leishmaniasis. Transactions of the Royal Society of Tropical Medicine and Hygiene, vol. 85, no. 4, pp. 457-464.

[4] Abdalla, R. E. and Sherif, H. (1978). Epidemic of cutaneous leishmaniasis in northern Sudan. Annals of Tropical Medicine \& Parasitology, vol. 72, no. 4, pp. 349-352.

[5] Abdalla, R. E., El Hadi, A., Ahmed, M. A., et al. (1975). Sudan mucosal leishmaniasis. Transactions of the Royal Society of Tropical Medicine and Hygiene, vol. 69, no. 5-6, pp. 443-449.

[6] Wu. W. K., Wang, G., Coffelt, S. B., et al. (2010). Emerging roles of the host defense peptide LL-37 in human cancer and its potential therapeutic applications. International Journal of Cancer, vol. 127, no. 8, pp. 1741-1747.

[7] Gallo, R. L. and Nizet, V. (2003). Endogenous production of antimicrobial peptides in innate immunity and human disease. Current Allergy and Asthma Reports, vol. 3, pp. 402-409.

[8] Huang, H. J., Ross, C. R., and Blecha, F. (1997). Chemoattractant properties of PR-39, a neutrophil antibacterial peptide. Journal of Leukocyte Biology, vol. 61, pp. 624-629. 
[9] De, Y., Chen, Q., Schmidt, A. P., et al. (2000). LL-37, the neutrophil granule- and epithelial cell-derived cathelicidin, utilizes formyl peptide receptor-like 1 (FPRL1) as a receptor to chemoattract human peripheral blood neutrophils, monocytes, and $T$ cells. Journal of Experimental Medicine, vol. 192, pp. 1069-1074.

[10] Heilborn, J. D., Nilsson, M. F., Kratz, G., et al. (2003). The cathelicidin anti-microbial peptide LL-37 is involved in reepithelialization of human skin wounds and is lacking in chronic ulcer epithelium. Journal of Investigative Dermatology, vol. 120, pp. 379389.

[11] Yang, Y. H., Wu, W. K., Tai, E. K., et al. (2006). The cationic host defense peptide rCRAMP promotes gastric ulcer healing in rats. Journal of Pharmacology and Experimental Therapeutics, vol. 318, pp. 547-554.

[12] Zasloff, M. (2002). Antimicrobial peptides of multicellular organisms. Nature, vol. 415, no. 6870, p. 389.

[13] Vandamme, D., Landuyt, B., Luyten, W., et al. (2012). A comprehensive summary of LL-37, the factotum human cathelicidin peptide. Cellular Immunology, vol. 280, no. 1, pp. 22-35.

[14] Bucki, R., Leszczyńska, K., Namiot, A., et al. (2010). Cathelicidin LL-37: a multitask antimicrobial peptide. Archivum Immunologiae et Therapiae Experimentalis, vol. 58, no. 1 , pp. 15-25.

[15] Kulkarni, M. M., Barbi, J., McMaster, W. R., et al. (2011). Mammalian antimicrobial peptide influences control of cutaneous Leishmania infection. Cell Microbiology, vol. 13, pp. 913-923. 